\title{
Cooperative Transition-Metal and Chiral Brønsted Acid Catalysis
}

Metal-Catalyzed Asymmetric Synthesis and Stereoselective

Reactions

\section{Key words}

asymmetric catalysis

hydrogenation

imines

iron

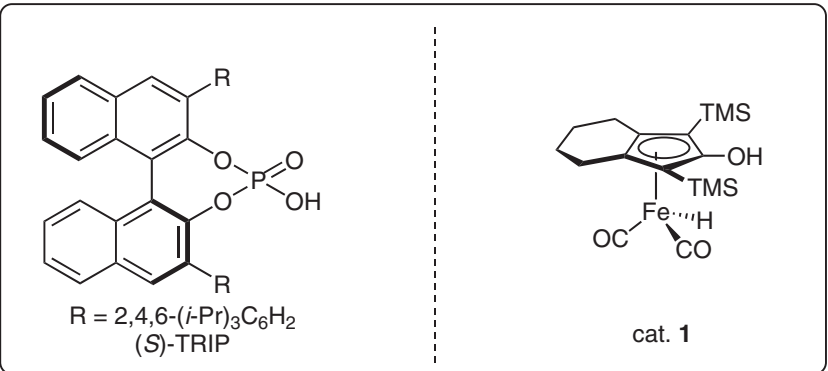

Selected examples:<smiles>CC(Nc1ccccc1)c1ccccc1</smiles>

$80 \%$ yield $94 \%$ ee<smiles>COc1ccc(C(C)Nc2ccccc2)cc1</smiles>

\section{$60 \%$ yield} $93 \%$ ee<smiles>CC(NP)c1cccs1</smiles>

$91 \%$ yield $93 \%$ ee<smiles></smiles>

$91 \%$ yield $83 \%$ ee

Proposed reaction intermediates:

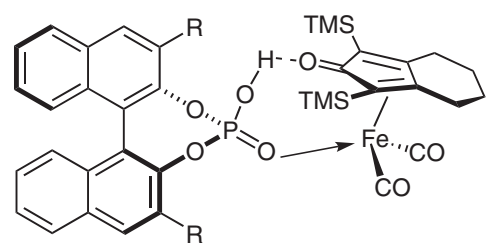

complex 1

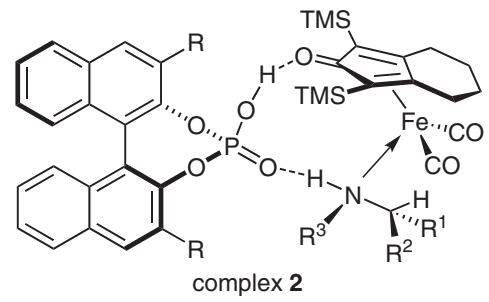

Significance: The authors report a protocol for the enantioselective hydrogenation of various ketimines in the presence of a chiral Bronsted catalyst and a well-defined nonchiral iron catalyst. This work demonstrates that enantioselective reduction reactions with hydrogen can be performed without employing precious-metal catalysts and chiral ligands yielding products with high yields and enantioselectivities.
Comment: NMR spectroscopic studies revealed the formation of complex $\mathbf{1}$ when a 1:1 mixture of TRIP and the Knölker iron complex (cat. 1) were mixed. Upon addition of a ketimine to the reaction mixture, the formation of complex $\mathbf{2}$ was observed. These results suggest that a cooperative catalytic system is operative for this transformation.

SYNFACTS Contributors: Mark Lautens, Patrick T. Franke DoI: 10.1055/s-0030-1260735; Reg-No.: L07611SF 